\title{
Intra-peritoneal administration of Ecballium elaterium diminishes postoperative adhesions ${ }^{1}$
}

\author{
Mehmet Hanifi Okur ${ }^{\mathrm{I}}$, Bahattin Aydogdu" Mehmet Serif Arslan" ${ }^{\mathrm{III}}$, Ulaş Alabalik ${ }^{\mathrm{IV}}$, Serkan Arslan" ${ }^{\mathrm{II}}$, İbrahim Kara ${ }^{\mathrm{V}}$, Fethiye \\ Canpolat $^{\text {VI }}$, Atalay Şahin ${ }^{\text {VII }}$, Selçuk Otcu ${ }^{\text {III }}$ \\ DOI: http://dx.doi.org/10.1590/S0102-8650201400160003
}

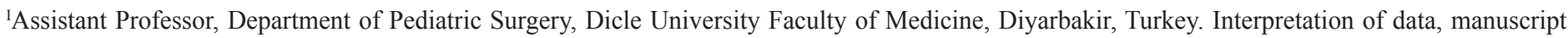
writing, critical revision.

IIAssistant Professor, Department of Pediatric Surgery, Dicle University Faculty of Medicine, Diyarbakir, Turkey. Interpretation of data.

IIIAssistant Professor, Department of Pediatric Surgery, Dicle University Faculty of Medicine, Diyarbakir, Turkey. Interpretation of data, critical revision.

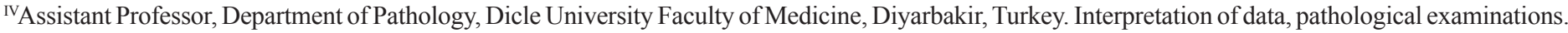

vAssistant Professor, Department of Biochemistry, Dicle University Faculty of Medicine, Diyarbakir, Turkey. Interpretation of data, biochemical analysis of the products.

${ }^{\mathrm{V}}$ Specialist, Department of Pediatric Surgery, Dicle University Faculty of Medicine, Diyarbakir, Turkey. Interpretation of data.

VIIAssistant Professor, Department of Thoracic Surgery, Health School, Dicle University Faculty of Medicine, Diyarbakir, Turkey. Interpretation of data, critical revision.

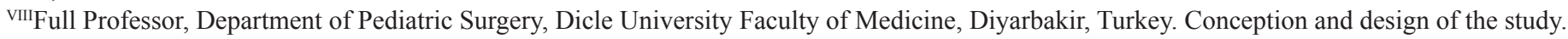

\begin{abstract}
PURPOSE: To evaluate the effects of Ecballium elaterium (EE), Elaterium officinarum, in postoperative intraperitoneal adhesions in rats. METHODS: Thirty rats were divided into three groups and underwent midline laparotomy under $35 \mathrm{mg} / \mathrm{kg} \mathrm{ketamine} \mathrm{and} 5 \mathrm{mg} / \mathrm{kg}$ xylazine anaesthesia. In group $1(n=10)$, the sham operation group, the abdominal walls were closed without any process. In group 2 $(n=10)$, the control group, the antimesenteric border of the ceacum and the corresponding parietal peritoneum were abraded with dry sterile gauze. In group $3(\mathrm{n}=10)$, the EE group, $2.5 \mathrm{mg} / \mathrm{kg}$ dose of EE was administered as intraperitoneally to the rats after abrasion. All rats were sacrificed on postoperative day 15 . Samples were obtained

RESULTS: The adhesion score was significantly decreased in the EE group $(p=0.001)$ in comparison with the control group. Microscopically, the EE and sham groups were significantly lower than that of the control group ( $\mathrm{p}<0.001$ and $\mathrm{p}=0.000$, respectively). Furthermore, the measurement of tissue levels of hydroxyproline was significantly lower in the sham and EE groups compared to the control group (sham group: $47.6 \pm 10.6$, EE group: 62.9 \pm 9.7, Control group: $84.2 \pm 22.1 \mathrm{mg} / \mathrm{L} / \mathrm{g}$-tissue).
\end{abstract}

CONCLUSION: The grade and severity of abdominal adhesion could be significantly reduced through administered Ecballium elaterium and therefore be a suitable anti-inflammatory agent for the prevention of postoperative peritoneal adhesion in the future.

Key words: Elaterium officinarum. Peritoneum, Adhesion, Anti-Inflammatory Agents. Rats. 


\section{Introduction}

Postoperative peritoneal adhesions (PPAs) are pathologic fibrotic bands formed between the omentum, intestinal loops, and abdominal wall or at any surface of the peritoneal cavity. PPAs lead to intestinal obstruction and atypical abdominal pain, intestinal and enterocutaneous fistula formation, difficulty in relaparotomy procedures, infertility in women, increased workloads during surgery, and increased costs in the health system ${ }^{1-4}$. The likelihood of intra-abdominal adhesion development has been reported as 67-93\% after all laparotomies and $3 \%$ of all laparotomies are due to PPAs ${ }^{5,6}$. In recent years, surgical techniques, mechanical barriers, and various agents have been proposed in order to overcome this severe problem ${ }^{7}$. The pulp of Ecballium elaterium (EE), a herbaceous plant from the Cucurbitaceae family, is traditionally used for the treatment of sinusitis in Anatolian folk medicine. It also has well-known hydragogue cathartic, antitumor, antimicrobial, and anti-inflammatory effects ${ }^{8,9}$. In this study, we planned to investigate the effects of EE in preventing PPA in an animal model.

\section{Methods}

The study was approved by the Animal Ethics Committee of Dicle University School of Medicine. Thirty male Wistar albino rats weighing 250-300g were used. The rats were kept in cages under controlled conditions (temperature $20-22^{\circ} \mathrm{C}$, relative humidity $60-80 \%$, and on a 12 -h light-dark cycle) with a balanced pellet diet and water. The rats were supplied by the animal house unit at Dicle University.

\section{Plant materials}

The ripe fruits of EE were picked in the Izmir forests during October 2012. The fruits were homogenized and then sliced and mixed. Exposure to light was avoided to prevent the loss of active ingredients. Approximately $50 \mathrm{~g}$ of minced material were mixed thoroughly within $200 \mathrm{~mL}$ of $80 \%$ ethanol at room temperature and left to rest for $24 \mathrm{~h}$. The insoluble materials were removed by vacuum filtration through Whatman paper. The ethanol in the extract was subsequently removed by evaporation and the extract was freeze dried at $-80^{\circ} \mathrm{C}$. The extract was weighed and dissolved in sterile isotonic solution at a concentration of $100 \mathrm{mg} / \mathrm{mL}$ and stored in the refrigerator at $8^{\circ} \mathrm{C}$ until its use for animal experiments.

\section{Anaesthesia and surgical procedures}

Animals were divided into three groups. The animal groups were anesthetized by intramuscular injection of $35 \mathrm{mg} /$ $\mathrm{kg}$ ketamine (Ketalar; Eczacıbaşı, Istanbul, Turkey) and $5 \mathrm{mg} /$ kg xylazine (Rompun; Bayer, Istanbul, Turkey). A 3-cm midline incision was performed in the anterior abdominal wall under sterile conditions and the absence of adhesions was confirmed with laparotomy. The antimesenteric border of the ceacum and the corresponding parietal peritoneum were then abraded with dry sterile gauze until punctate bleeding occurred. Following abrasion, the abdominal wall was closed by a running suture with 3/0 atraumatic silk.

\section{Experimental groups}

In this study, rats were analysed in three groups with 10 rats in each. Group 1 (sham group), underwent no procedures following confirmation of the absence of intraperitoneal adhesions. Group 2 (control group), underwent abrasion of the antimesenteric border of the ceacum and the corresponding parietal peritoneum with dry sterile gauze until petechial bleeding foci were observed. Group 3 (EE group), underwent abrasion of the antimesenteric border of the ceacum and the corresponding parietal peritoneum with dry sterile gauze until petechial bleeding foci were observed and was then treated with a $2.5 \mathrm{mg} / \mathrm{kg}$ dose of EE administered intraperitoneally. For all groups, the abdominal wall was closed following the respective treatments. On postoperative 15 day, the rat abdomens were opened again under anaesthesia through a U-shape incision. Following sampling for macromorphologic and histopathologic evaluation and tissue hydroxyproline levels, rats were euthanized by drawing blood via a cardiac puncture.

\section{Assessment of adhesion}

The severity of the adhesions in the macroscopic evaluation was graded according to the system employed by Nair et $a l .{ }^{10}$. The ceacum and adherent abdominal wall were then sent for histopathologic evaluation and tissue hydroxyproline levels.

\section{Histopathologic evaluation}

Pathology specimens were fixed in plates containing $10 \%$ buffered formaldehyde and embedded into paraffin blocks; $5-\mu \mathrm{m}$ thick sections were cut. Specimens were stained with hematoxylin-eosin and examined under light microscopy using a 
Nikon Eclipse 80i microscope. Histopathologic evaluation of the adhesions was performed by an investigator blinded to the study according to the method of Zuhlke et al. ${ }^{11}$ (Table 1).

TABLE 1 - Results of in-group statistical assessment.

\begin{tabular}{lcccccccccc} 
Groups & \multicolumn{2}{c}{$\begin{array}{c}\text { Macroscopic } \\
\text { Adhesion score } \\
\left(\text { Nair } \text { et } \text { al. }{ }^{10} \text { ) }\right.\end{array}$} & $\begin{array}{c}\text { Microscopic } \\
\text { Adhesion score } \\
\text { (according to } \\
\text { (Zühlke } \text { et al. }{ }^{11} \text { ) }\end{array}$ & $\begin{array}{c}\text { OH-p } \\
\text { levels } \\
\text { mean } \pm \text { SD }\end{array}$ \\
\hline Grade & $\mathbf{0}$ & $\mathbf{1}$ & $\mathbf{2}$ & $\mathbf{3}$ & $\mathbf{4}$ & $\mathbf{1}$ & $\mathbf{2}$ & $\mathbf{3}$ & $\mathbf{4}$ & \\
\hline $\begin{array}{l}\text { Sham } \\
(\mathbf{n = 1 0})\end{array}$ & 6 & 3 & 1 & - & - & 8 & 2 & - & - & $47.6 \pm 10.6$ \\
$\begin{array}{l}\text { Control } \\
(\mathbf{n}=\mathbf{1 0})\end{array}$ & - & - & 2 & 7 & 1 & - & 3 & 7 & & $84.2 \pm 22.1$ \\
EE $(\mathbf{n = 1 0})$ & 2 & 5 & 2 & 1 & - & 7 & 3 & - & - & $62.9 \pm 9.7$ \\
\hline
\end{tabular}

\section{Determination of tissue hydroxyproline levels}

One gram of specimen was hydrolysed in $1 \mathrm{~mL}$ of acidic buffer at $121^{\circ} \mathrm{C}$ for $5 \mathrm{~h}$ and centrifuged at $5.000 \mathrm{rpm}$ for $20 \mathrm{~min}$. Absorbance of the formed material was evaluated at 560 $\mathrm{nm}$ at $121^{\circ} \mathrm{C}$ with a colorimetric (photometric) method and tissue hydroxyproline levels were calculated as $\mathrm{mg} / \mathrm{L} / \mathrm{g} / \mathrm{tissue}$.

\section{Statistical analysis}

Statistical analysis was performed using SPSS 15.0 software. The Kruskal-Wallis test was used to compare multiple independent samples. When a significant difference was detected, two independent samples were evaluated by a Mann-Whitney U-test for paired in-group comparison and Bonferroni correction was performed for in-group comparison. A $p$ level of 0.0167 was accepted as significant.

\section{Results}

A total of 30 rats were operated. No wound dehiscence or incisional hernias were observed. A significant difference was detected between groups in terms of macroscopic and microscopic findings and tissue hydroxyproline levels as assessed by the Kruskal-Wallis method ( $p=0.001, p<0.001, p<0.001$ respectively). In in-group comparison with the Mann-Whitney U-test, a significant difference was detected between the EE and sham groups and the control group ( $\mathrm{p}=0.001$ and $\mathrm{p}=0.011$, respectively) macroscopically (Figure 1).

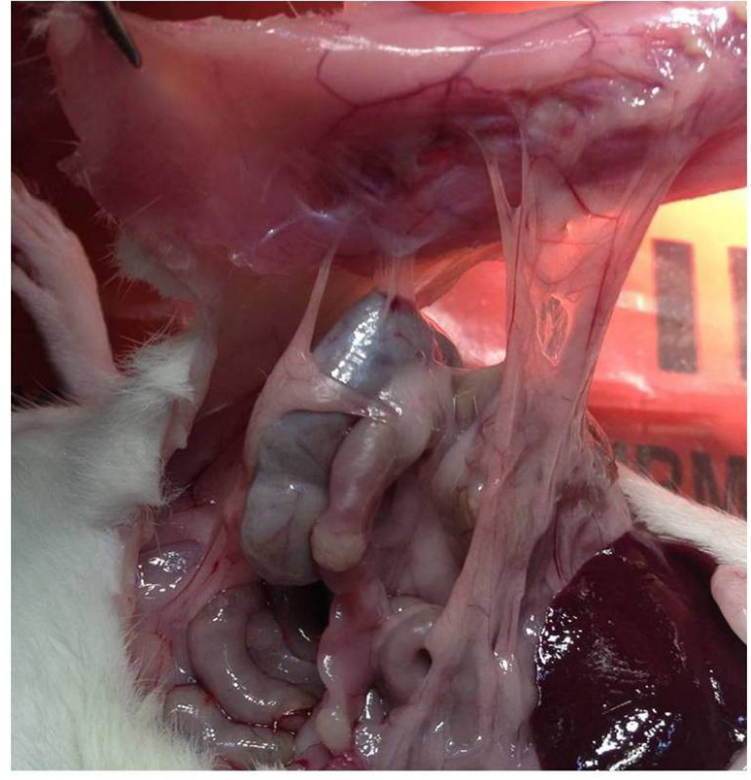

FIGURE 1 - The macroscopic finding of control group, appearance of grade 3 adhesion.

When groups were compared microscopically according to the Zuhlke classification (Figure 2), significant differences were detected between the EE and sham groups and the control group $(\mathrm{p}<0.001$ and $\mathrm{p}=0.000$, respectively). When inter-group hydroxyproline levels were analysed, it was significantly lower in the EE and sham groups compared to the control group (sham group $=47.6 \pm 10.6$, EE group $=62.9 \pm 9.7$, control group $=84.2 \pm$ 22.1, respectively) (group scores and differences between groups are shown in Table 1).

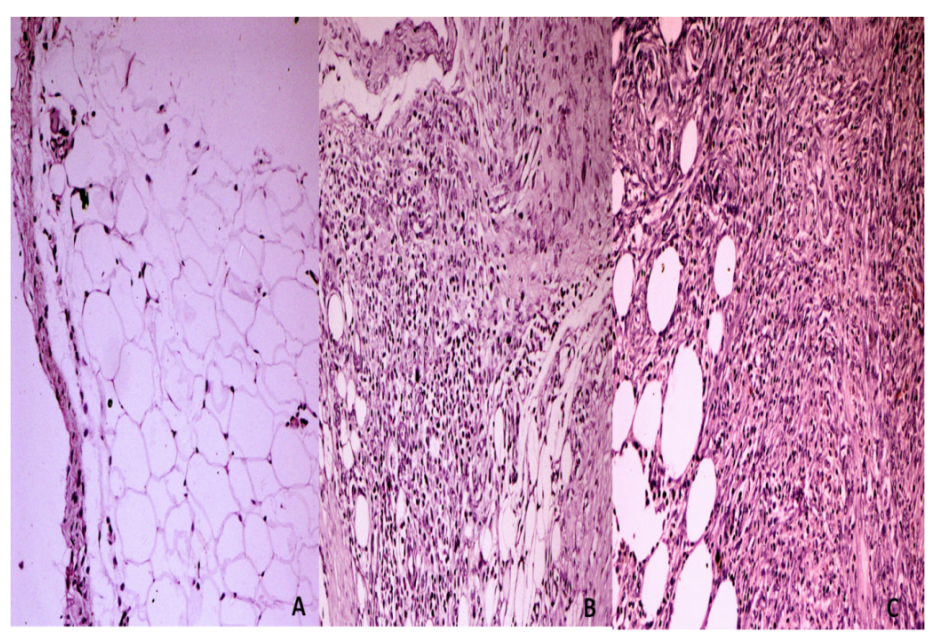

FIGURE 2 - Microscopic findings, appearance of grade 1 (A), 2 (B) and grade $3(\mathbf{C})$ adhesion respectively (H\&E, x100). 


\section{Discussion}

Adhesions are the result of physiologic wound healing which develops on peritoneal surfaces due to inflammation, increases in vascular permeability and immune cells, and extravasation of fibrin deposits against trauma, ischemia, infection, and foreign bodies ${ }^{1}$. Inflammation leads to the formation of a fibrin-rich serohemorrhagic exudate. Fibrinolytic activity usually hinders rapid adhesion formation; therefore, if fibrinolytic capacity is insufficient, adhesions develop ${ }^{12}$. Adhesions are a severe postoperative complication and may develop even years after a surgical procedure; they are a cause of significant morbidity that may result in multiple complications ${ }^{13,14}$ and incur significant economic effects due to loss of productivity, prolonged duration of hospital stay, and additional surgical procedures, besides the obvious harm on human health ${ }^{15}$. There is, as yet, no clear strategy for the prevention of adhesions ${ }^{16}$. However, several studies have focused on reducing inflammatory responses and blocking fibroblastic activity $^{17,18}$. Fibrinolysis seems to be a key factor in determining the pathogenesis of adhesion formation and in its prevention. Researchers have used many anti-inflammatory agents, including chemical and pharmacologic agents, as well as mechanical and physical barriers in order to prevent adhesion ${ }^{18-19}$. However, despite positive reports, these methods are not used in standard practice. Tenoxicam has been shown to inhibit and prevent fibrin formation in a study of intra-abdominal adhesion using a rat model $^{18}$.

$\mathrm{EE}$ is a herbaceous plant from the Cucurbitaceae family. Pulps and ointments prepared from its roots are used against tumours, chronic skin wounds like eczema, and rheumatic pain. Although it leads to uvula oedema when used nasally in high doses and without diluting, in Anatolia, the fresh pulp is commonly used against sinusitis by squeezing the fruit and sniffing it. In a clinical study, Yeşilada et al. ${ }^{20}$ revealed that EE showed anti-inflammatory effects by reducing the production of chemotaxis factors such as TNF- $\alpha$, IL-1, and IL-6. Uslu et al. ${ }^{21}$ showed that it suppressing anti-inflammatory effects by inhibition of nitric oxide synthase activity. Therefore, we consider that EE prevented PPA formation through its anti-inflammatory effects. In our study, macroscopic and microscopic adhesion scores were significantly lower for the EE group compared to the control group. In addition, levels of hydroxyproline, a component of collagen, were high in the control group given that adhesions develop due to collagen accumulation.

\section{Conclusions}

The intraperitoneally administered Ecballium elaterium is not irritating for the intestines and that its adhesion-reducing properties are due to the abovementioned anti-inflammatory effect that it exerts. Ecballium elaterium may therefore be a suitable antiinflammatory agent for the prevention of postoperative peritoneal adhesion. However, preclinical and clinical studies are required in order to ascertain effective dose intervals and mechanisms of action, and to compare its effectiveness with other agents.

\section{References}

1. Menzies D, Ellis H. Intestinal obstruction forms adhesions: how big is the problem? Ann R Coll Surg Eng. 1990;72:60-3. PMID: 2301905.

2. Ellis H, Moran BJ, Thompson JN, Parker MC, Wilson MS, Menzies D, McGuire A, Lower AM, Hawthorn RJ, O'Brien F, Buchan $\mathrm{S}$, Crowe AM. Adhesion-related hospital readmissions after abdominal and pelvic surgery: a retrospective cohort study. Lancet. 1999;353:1476-80. PMID: 10232313.

3. Hers A, Diamond MP, DeCherney AH. Adhesiolysis. Clin Obstet Gynecol. 1991;34:395-8. PMID: 1831077.

4. Afyez JA. An assessment of the role of operative laparoscopy in tuboplasty. Fertil Steril. 1983;39:476-9. PMID: 6219897.

5. Dijkstra FR, Nieuwenhuijzen M, Reijnen MM, van Goor H. Recent clinical developments in pathophysiology, epidemiology, diagnosis and treatment of intra-abdominal adhesions. Scand J Gastroenterol Suppl. 2000;232:52-9. PMID: 11232493

6. Liakakos T, Thomakos N, Fine PM, Dervenis C, Young RL. Peritoneal adhesions: etiology, pathophysiology, and clinical significance. Dig Surg. 2001;18:260-73. PMID: 11528133.

7. Arung W, Meurisse M, Detry O. Pathophysiology and prevention of postoperative peritoneal adhesions. World J Gastroenterol. 2011;17(41):4545-53. doi: 10.3748/wjg.v17. i41.4545.

8. Yesilada E, Tanaka S, Sezik E, Tabata M. Isolation of an antiinflammatory principle from the fruit juice of Ecballium elaterium. J Nat Prod. 1988;51(3):504-8. doi: 10.1021/np50057a008.

9. Adwan G, Salameh Y, Adwan K. Effect of ethanolic extract of Ecballium elaterium against Staphylococcus aureus and Candida albicans. Asian Pac J Trop Biomed. 2011;1(6):456-60. doi: 10.1016/ S2221-1691(11)60100-7.

10. Nair SK, Bhat IK, Aurora AR: Role of proteolytic enzymes in the prevention of postoperative intraperitoneal adhesions. Arch Surg. 1974;108:849-53. doi: 10.1001/archsurg.1974.01350300081019.

11. Zühlke HV, Lorenz EM, Straub EM, Savvas V. Pathophysiology and classification of adhesions. Langenbecks Arch Chir Suppl II Verh Dtsch Ges Chir. 1990;1009 -16. PMID: 1983476.

12. Aorons CB, Cohen PA, Gower A, Reed KL, Leeman SE, Stucchi $\mathrm{AF}$, Becker JM. Statins (HMG-CoA reductase inhibitors) decrease postoperative adhesions by increasing peritoneal fibrinolytic activity. Ann Surg. 2007;245:176-84. doi: 10.1097/01. sla.0000236627.07927.7c.

13. Parker MC. Epidemiology of adhesions: the burden. Hosp Med. 2004;65:330-6. PMID: 15222206.

14. Boland GM, Weigel RJ. Formation and prevention of postoperative abdominal adhesions. J Surg Res. 2006;132:3-12. PMID: 16457846.

15. Ray NF, Denton WG, Thamer M, Henderson SC, Perry S. Abdominal adhesiolysis: inpatient care and expenditures in the United States in 1994. J Am Coll Surg. 1998;186:1-9. PMID: 9449594.

16. Ray NF, Larsen JW Jr, Stillman RJ, Jacobs RJ. Economic impact of hospitalisations for lower abdominal adhesiolysis in the United States in 1988. Surg Gynecol Obstet. 1993;176:271-6. PMID: 8438200 
17. Thompson JN. Pathogenesis and prevention of adhesion formation. Br J Surg. 1995;82:3-5. PMID: 7881947.

18. Yilmazlar T, Kaya E, Gurpinar E, Emiroglu H. Efficacy of tenoxicam on intra-abdominal adhesion prevention in a rat model. J Int Med Res. 1996;24:352-7. PMID: 8854289.

19. Kaptanoglu L, Kucuk HF, Yegenoglu A, Uzun H, Eser M, Mentes $\mathrm{CV}$, Kurt N. Effects of seprafilm and heparin in combination on intra-abdominal adhesions. Eur Surg Res. 2008;41:203-7. doi: 10.1159/000134919.

20. Yeşilada E, Ustün O, Sezik E. Inhibitory effects of Turkish folk remedies on inflammatory cytokines: interleukin1alpha, interleukin-1beta and tumor necrosis factor alpha. J Ethnopharmacol. 1997;58(1):59-73. PMID: 9324006.

21. Uslu C, Karasen RM, Sahin F. Effect of aqueous extracts of Ecballium elaterium rich, in the rabbit model of rhinosinusitis. Int J Pediatr Otorhinolaryngol. 2006;70(3):515-8. doi: 10.1016/j. ijporl.2005.07.020.

\section{Correspondence:}

Mehmet Hanifi Okur

Department of Pediatric Surgery

Dicle University, Diyarbakir, Turkey

Phone: 0090 (533) 2597994

Phone: 0090 (412) 2488001

m.hanifi-okur@hotmail.com

Received: May 27, 2014

Review: July 25, 2014

Accepted: Aug 26, 2014

Conflict of interest: none

Financial source: none

${ }^{1}$ Research performed at Experimental Animal Laboratory, Dicle University, Diyarbakir, Turkey. 